\title{
Grade Medical Officers perception towards lifelong learning; a mixed method study
}

\author{
Jayarathne, S.W. ${ }^{1}$, Marambe, K.N. ${ }^{2}$ \& Karunathilake, I.M. ${ }^{3}$
}

\begin{abstract}
Introduction: Baseline information on lifelong learning and CPD activities of Grade Medical Officers (GMOs) are essential to develop CPD provision guidelines. The aim of this study was to find out baseline information on lifelong learning and CPD activities of GMOs.

Method: A complementarity design was used to collect baseline information regarding lifelong learning and CPD activities of GMOs. Data were collected from grade medical officers and CPD leads. A tailor made questionnaire was used to collect data from $422 \mathrm{GMOs}$ representing different hospital categories in the Central Province. Island wide CPD leads (38) were inquired on organization of CPD for doctors through a semi structured interview. The frequencies were calculated for quantitative data and qualitative data were analysed by means of content analysis.
\end{abstract}

Results: A vast majority of GMOs (98\%) perceived CPD as a requirement although around $50 \%$ were willing to undertake mandatory CPD. The preferred learning methods of the GMOs' were reading $(21.0 \%)$, work based learning (17.5\%), problem solving approach (16.9\%) and interactive approach $(14.9 \%)$ respectively. The most prominent among the revealed 27 recently practiced learning methods were, "discussing with seniors" (40.4\%), "reading" (27.1\%) and "e learning" (15.4\%). Learning needs of GMOs seem to be averagely addressed in major hospitals while it is reported to be poorly addressed in peripheries. The majority of the CPD organizing bodies indicated that they were not that satisfied with the CPD activities provided by them and it also revealed that structured CPD activities through needs analysis with proper planning and feedback are yet to be developed in Sri Lanka. Issues of funding, lack of resources, lack of motivation and poor support from the higher authorities were identified as challenges for CPD provision.

Conclusions: GMOs' perceive CPD as a dire need, most preferred learning methods and their practiced learning methods rely so much on immediately available learning resources, which have characteristics of familiarity, applicability and accessibility. The majority of CPD organizing bodies in Sri Lanka is yet to establish an objective driven plan for CPD.

Key words: CPD, CME, Lifelong learning, Learning needs, Learning theories

\section{Introduction}

Lifelong learning is described as "continuation of medical education with an ongoing process of professional development, which is closely linked to self-assessment that allows physicians to maintain requisite knowledge, skills and professional standards" (Madewell, 2004).

\footnotetext{
${ }^{1}$ Senior Lecturer, Head, Medical Education Unit, Faculty of Medicine and Allied Sciences, Rajarata University Sri Lanka ${ }^{2}$ Professor, Head, Medical Education Unit, Faculty of Medicine, University of Peradeniya

${ }^{3}$ Professor, Head, Department of Medical Education, Faculty of Medicine, University of Colombo

Corresponding Author:

Jayarathne $S W$

Senior Lecturer, Head, Medical Education Unit, Faculty of Medicine and Allied Sciences, Saliyapura

Email -wjayaratna@yahoo.com
}

CPD is defined as any learning outside undergraduate education or postgraduate training that helps you maintain, improve your performance. It covers the development of doctors' knowledge, skills and attitudes and behaviors across all areas of one's professional practice. It also includes both formal and informal learning activities (GMC, 2012). Hence, lifelong learning remains an excellent tool for CPD. Since practice of medicine and its underlying knowledge are changing considerably (Towle, 1996) dedication to lifelong learning and being up to date with changing medical practices should be the commitment of every doctor (Rancich et al., 2005; Bandaranayake, 2009).

It is reasonable to state that government policies in relation to CPD development are at

SEAJME. This is an Open Access article distributed under the terms of the Creative Commons Attribution License (http://creativecommons.org/licenses/by/4.0/), which permits unrestricted use, distribution, and reproduction in any medium, provided the original author and source are credited 
an evolutionary stage in Sri Lanka. According to the Sri Lankan literature, it is evident that, SLMC has proposed amendments to the medical ordinance to make revalidation a legal requirement (Epa, 2003). Furthermore, towards its realization the Sri Lanka Medical Association (SLMA) has appointed a revalidation committee in 2003 and several discussions have been held in this regard within SLMA and SLMC, first to initiate a systematic CPD program with the hope of moving towards a system of revalidation later. As a result of these discussions, the National CPD Certificate was proposed by the SLMA and subsequently National Center for CPD in Medicine (NCCPDIM) was established under the SLMA (Epa, 2003).

It is also noted that subsequent to several discussions, the National CPD Certificate programme has commenced in 2010 (National CPD Certificate, 2010). This certificate is issued by NCCPDIM indicating the CPD status of an individual doctor. Currently, the certificate is voluntary. Therefore, the current status with regard to CPD in Sri Lanka is that an individual doctor can apply for the National CPD Certificate and on fulfilling the criteria, the CPD certificate will be issued by the NCCPDIM. Thus, it can be concluded that physicians in Sri Lanka - GMOs or after being qualified as specialists, could continue their career with or without engaging in CPD activities.

A few studies have been published in Sri Lanka with respect to CPD of doctors (Epa, 2003). However, there has not been an analysis of lifelong learning preferences, practiced learning methods, learning needs, promoting and inhibiting factors of CPD among non-specialist doctors. Further, the degree of enthusiasm for engaging in CPD activities among GMOs is not known. Information on availability of opportunities for CPD in different health care institutes is also hard to find. Thus, there is a felt need to document the background information of current CPD status and lifelong learning practices of doctors in order to develop streamline CPD programmes in Sri Lanka.

In this background, a descriptive study was planned to assess and document the current status of CPD among GMOs representing all the health care institutes of the Central Province of Sri Lanka and an exploratory study was planned with CPD providers in Sri Lanka. This study was conducted to answer the following research questions:
1. What are the lifelong learning practices among GMOs in the Central Province of Sri Lanka?

2. What is the level of CPD awareness and perceptions of GMOs in the Central Province of Sri Lanka?

3. How do CPD providers in different CPD organizing bodies contribute to CPD activities of GMOs?

The study focuses on GMOs due to the fact that they are the sole health care providers in some hospital categories such as divisional hospitals, primary medical care units and Medical Officer of Health officers. The training of doctors of these institutes has a great impact on the quality of services offered at grass root level. Hence, the results of the study have the potential to help the CPD organizers to understand the CPD process and lifelong learning of GMOs that could be used for planning of future CPD activities.

\section{Special note}

Lifelong learning practices cover areas of best learning methods, practiced learning methods, lifelong learning preferences and learning needs.

CPD awareness and perceptions cover areas of knowledge and understanding the concept of $C P D, C P D$ provider and National CPD Certificate, about CPD activities and attitudes towards CPD.

\section{Methods}

The present study incorporated a complementarity design where qualitative and quantitative methods were used to measure overlapping but also different facets of the same phenomenon (Greene et al., 1989), which is CPD of GMOs, yielding an elaborated understanding of the CPD of GMOs. The purpose of the complementarity design studies is to increase the interpretability, meaningfulness, illustration and clarification of results from one method with the results from the other method (Greene et al., 1989). The questionnaire (Annexure 1) was used to obtain data from grade medical officers. The probability proportional to the size, multistage sampling procedure was used to select the 422 GMOs from the different health care institutes in the Central Province. The variables of the questionnaire were mainly identified according to the objectives of the study, by literature 
review by participating in symposia and seminars related to CPD of doctors and also from the experts' opinion. The questionnaire consisted of two broad components. Personal and background information were considered as non-threatening and placed at the Section A at the first part of the questionnaire. The Section B, consisting questions on best learning methods, lifelong learning preferences, practiced learning methods, learning needs, issues of addressing the learning needs and CPD awareness and perceptions.

"Preferred learning methods refer to the best ways of learning as indicated by the physicians among the many methods available to them"

"Practiced learning methods refer to recently practiced learning methods; it could be the best learning methods or the methods selected by the physician based on available resources, which suit the immediate learning need"

Judgmental validity was considered as the minimum prerequisite of acceptance of a measure (Abramson \& Abramson, 1999). Hence judgmental validity was assured. The questionnaire was pretested among a group of grade medical officers. Few changes were made with regard to wording of questions further, order of the questions were changed and few questions were eliminated. The questionnaire items in the present study were designed to obtain the views and perceptions of grade medical officers and not to measure an attribute.

Thus, measurement of internal consistency is not applicable for the present study. Therefore, only the test - retest reliability was checked. Five selected questions were given to the 20 GMOs by a two weeks interval and 10 questionnaires were returned. All the questionnaires were manually checked for marking the same item as in the previous questionnaire. The similarities between the answers to the same question were checked as a percentage. Since, agreement between the questionnaires was above $70 \%$, the questionnaire can be taken as a reliable measure.

The second component of the project (Study 2) involved an island wide interview study among majority CPD leads to identify the current process of organizing CPD activities. Semistructured interviews were conducted through both telephone and through face to face. It felt that, telephone interviews were the best since the interview duration was short (Novick, 2008) and most of the questions were simple enough to be understood by the recipient who was a medical officer, in order to provide an answer through telephone. Similar to the questionnaire, interview guide was prepared for Sri Lankan context. It was prepared based on literature and also considering the views from the experts. The guide was pretested conducting three interviews and minor changes were made to the guide.

Ethical approval for the study was taken from Ethics review committee, Faculty of Medicine, University of Peradeniya.

\section{Results}

The response rates were (91.9\%) and (68.5\%) for the questionnaire study and the interview study respectively. Table 1 and 2 illustrates the socio demographic data of GMOs and CPD leads.

\section{Study 1}

Table 3 depicts the lifelong learning practices and level of CPD awareness and perceptions among GMOs. Majority of the GMOs (98\%) perceived CPD as a requirement although only a half of them were willing to undertake mandatory CPD activities. A majority (83\%) of GMOs were unaware about the National CPD certificate. The preferred learning methods of the GMOs' in the Central Province were reading $(21.0 \%)$, work based learning (17.5\%), problem solving approach (16.9\%) and interactive approach $(14.9 \%)$ respectively. Total of 27 recently practiced learning methods could be categorized into "discussing with seniors" (40.4\%), "reading" (27.1\%) and "e learning" (15.4\%). However, rural sector doctors indicated that reading $(27.1 \%)$ and discussing with their colleagues $(27.1 \%)$ as practiced learning methods. The preferred three CPD activities were reading medical text books $(20.0 \%)$, learning during work from seniors $(16.5 \%)$ and e-learning (15.5\%) respectively. 
Table 1: Socio- demographic data of GMOs

\begin{tabular}{|c|c|c|c|c|c|c|c|c|}
\hline Characteristic & $\mathrm{TH}^{*}$ & $\mathrm{DGH}^{\varepsilon}$ & $\mathrm{BH}^{\dagger}$ & $\mathrm{DH}^{\ddagger}$ & PMCUx & $\mathrm{MOH}^{\mathrm{F}}$ & $\begin{array}{l}\text { Special } \\
\text { unit } ¥\end{array}$ & Total \\
\hline No of respondents & 218 & 61 & 25 & 49 & 10 & 15 & 10 & $388(91.9 \%)$ \\
\hline \multicolumn{9}{|l|}{ Sex } \\
\hline - Male & 113 & 39 & 14 & 33 & 5 & 9 & 6 & $219(56.4 \%)$ \\
\hline - Female & 105 & 22 & 11 & 16 & 5 & 6 & 4 & $169(43.6 \%)$ \\
\hline Age range (years) & $27-53$ & $28-47$ & $27-38$ & $29-59$ & $27-43$ & $30-44$ & $29-45$ & \\
\hline $\begin{array}{l}\text { Number of GMOs with } \\
\text { postgraduate qualification }\end{array}$ & 68 & 20 & 10 & 12 & 3 & 1 & 4 & $118(30.4 \%)$ \\
\hline $\begin{array}{l}\text { Number of GMOs Studying } \\
\text { for Postgraduate exams }\end{array}$ & 44 & 2 & 1 & 9 & 0 & 3 & 2 & $61(15.7 \%)$ \\
\hline \multicolumn{9}{|c|}{ Graduated medical faculty (number of GMOs) } \\
\hline - Peradeniya & 123 & 32 & 6 & 32 & 5 & 8 & 6 & $212(54.6 \%)$ \\
\hline - Colombo & 19 & 3 & 5 & 5 & 1 & 1 & 2 & $36(9.3 \%)$ \\
\hline - Kelaniya & 26 & 11 & 6 & 6 & 1 & 3 & 0 & $53(13.6 \%)$ \\
\hline - Jaffna & 6 & 2 & 1 & 0 & 0 & 0 & 0 & $9(2.3 \%)$ \\
\hline - Jayawardanapura & 15 & 4 & 3 & 1 & 3 & 1 & 0 & $27(6.9 \%)$ \\
\hline - Ruhuna & 13 & 5 & 1 & 4 & 0 & 0 & 1 & $24(6.1 \%)$ \\
\hline - Foreign & 14 & 4 & 3 & 1 & 0 & 2 & 0 & $24(6.1 \%)$ \\
\hline
\end{tabular}

Note: ${ }^{*}$ Teaching Hospitals in Kandy district (Teaching hospital Kandy, Teaching hospital Peradeniya, Teaching hospital Gampola, SirimavoBandaranayake Children's Hospital, Peradeniya), £ District General Hospitals in Kandy, Matale and Nuwaraeliya districts ( DGH Nawalapiya, DGH Matale , DGH Nuwaraeliya), † Base Hospitals in Matale and Nuwaraeliya districts (Base Hospital Dambulla , Base Hospital Dickoya), ¥ Divisional Hospitals in Kandy, Matale and Nuwaraeliya districts, $x$ Primary Medical Care Units in Kandy, Matale and Nuwaraeliya districts (PMCU), FMedical Officers of Health in Kandy, Matale and Nuwaraeliya districts, $¥$ Special Care units in Kandy and Nuwaraeliya districts

Table 2: Socio- demographic data of CPD leads

\begin{tabular}{lcc}
\hline CPD organizing bodies in Sri Lanka- 2013/2014 & Total Number & $\begin{array}{c}\text { The number of } \\
\text { organizations } \\
\text { Interviewed }\end{array}$ \\
\hline Clinical societies (mainly hospital based) & 47 & 36 \\
\hline $\begin{array}{l}\text { Other CPD organizations (Colleges, Sri Lanka Medical } \\
\text { Association, Health Education Bureau etc.) }\end{array}$ & $29(23$ colleges ) & 12 \\
\hline
\end{tabular}


Table 3: Results of Study 1

\begin{tabular}{|c|c|}
\hline Category & Results \\
\hline Preferred learning methods & $\begin{array}{l}\text { Reading }(21.0 \%) \text {, } \\
\text { Work based learning (17.5\%), } \\
\text { Problem solving approach (16.9\%) } \\
\text { Interactive approach }(14.9 \%)\end{array}$ \\
\hline Practiced learning methods & $\begin{array}{l}\text { Discussions with seniors (40.4\%), } \\
\text { Reading }(27.1 \%) \\
\text { E learning }(15.4 \%) \\
\text { Rural GMOs - discussion with their colleagues }(27.1 \%)\end{array}$ \\
\hline Preferred three CPD activities & $\begin{array}{l}\text { Reading medical text books }(20.0 \%) \\
\text { Learning during work from seniors }(16.5 \%) \\
\text { E learning }(15.5 \%)\end{array}$ \\
\hline Identified CPD needs & $\begin{array}{l}\text { Management of routine cases }(33.9 \%) \\
\text { Management of emergencies }(33.3 \%) \\
\text { Updates of both clinical and non-clinical cases }(11.6 \%) \\
\text { Personality development }(6.4 \%) \\
\text { Research }(2.8 \%)\end{array}$ \\
\hline Motivational factors for attending CPD & $\begin{array}{l}\text { Career progression }(30.6 \%) \\
\text { Due to discrepancies of knowledge/skills identified by them }(19.3 \%) \\
\text { Keen on professional development (17\%) }\end{array}$ \\
\hline Barriers for attending CPD & $\begin{array}{l}\text { Heavy workload }(30.6 \%) \\
\text { Lack of motivation }(18.8 \%) \\
\text { Difficulty in getting leave }(18.5 \%)\end{array}$ \\
\hline
\end{tabular}

The revealed learning needs of GMOs could be lumped under seven major categories. Those were: management of emergencies, day to day management, current updates (both clinical and non-clinical), research, personality development, procedural skills and trauma management. It was found that learning needs were averagely addressed in Teaching Hospitals, District General Hospitals, Base Hospitals and special units while in peripheries it was low and most of the identified learning needs were in relation to the practice needs. It was also reported that none of the formal CPD activities have been conducted in the peripheries. Career progression was identified as a positive factor for CPD while excessive work load was the main barrier.

\section{Study 2}

A majority of the CPD organizing bodies was not satisfied with the kind of CPD activities provided by them. Didactic clinical lectures were the commonest form of CPD activity conducted in Sri Lanka. It was also revealed that learning needs were mainly decided on the experts' opinion rather than through an exploration of the perceived learning needs of individual members. Further, structured CPD activities with proper planning, notification, feedback mechanism and learning needs analysis are yet to be developed by the CPD providing organizations in Sri Lanka. In addition, some of CPD leads were unaware of the existence of the National CPD Certificate. Issues of funding, lack of resources, lack of motivation and poor support from the higher authorities were reported as challenges for CPD provision.

\section{Discussion}

It is unarguable that the aim of CPD is to improve the practice behavior of physicians. According to recent evidence, effective CPD should be highly "self-directed with content, learning methods and learning resources to maintain or improve the knowledge, skills and attitudes needed in daily clinical practice" (Bennett et al., 2000). Therefore, CPD planners 
should understand the needs of learners especially with regard to preferred learning methods and preferred CPD activities in order to organize successful programs.

It is reasonable to conclude that GMOs in the Central Province have utilized the immediately available learning resources as well as familiar resources to update themselves. It is clear that their most familiar learning method turned out to be their preferred learning method. Learning preferences reported by emergency physicians of Australasia and Canadian general practitioners were more or less similar to the Sri Lankan study and selected methods were mainly based on the available learning resources which have characteristics of familiarity, applicability and accessibility (McClaren et al., 1998; Weiland et al., 2008). Yet another observation was that doctors continue using methods of learning, which they have practiced during the undergraduate period. Reading was reported as a popular learning method by all the doctors since most of the units were equipped with text books. Further, the revelation that a considerable number of doctors prefer problem solving approach and interactive learning, it can be argued that the preferred learning methods are more in line with the assumptions of adult learner as somebody who prefers self-directed learning. However, low preference for reflective practice is a cause for concern. Thus, it is worthwhile for CPD providers and higher authorities to find out preferred learning methods and make arrangements to provide appropriate learning resources in all the units of hospitals and thereby enhance the continuous learning process of doctors.

The study also revealed that most of the learning needs were in relation to practice needs of GMOs and very few seem to be interested in engaging in research and personality development. Interestingly, the perceived needs of general practitioners in Columbia and Physicians in America were consistent with the results of the present study (Craig, 1990; Thompson et al., 2002). Further, learning needs seem to be averagely addressed in $\mathrm{TH}, \mathrm{DGH}, \mathrm{BH}$ and special units while in peripheries it was low. In addition, experts play the main role in identifying learning needs. Thus, it reflects that individual learning needs have not been adequately addressed in most of the hospitals. Thus, it is time for the CPD organizers to change to a more participatory method for identification of learning needs of doctors and then relevant authorities to concentrate on ways and means of streamlining the process of CPD in Sri Lanka.

Lack of awareness of the National CPD Certificate among the surveyed doctors reflects the inadequacy of the promotion campaign. As suggested by some of the GMOs, higher authorities should try to incorporate a reward system such as include CPD points in grade promotion schemes, entitlement for allowances, duty leave, transfer facilities and incentives such as reimbursement of conference registration based on earned CPD credits. It is seen that most of the countries offer incentives for promotion of CPD activities. The USA and UK provide financial incentives for doctors (Clemens \& Gottlieb, 2013; Kingma, 1999). This fact has been confirmed by the WHO report in 2004, indicating that delay in the legislation process of $\mathrm{CME}$ in developing countries is due to lack of opportunity to participate in good quality CME, lack of motivation and lack of incentives (Sarkar \& Kumar, 2004). Thus, it is important for the higher authorities to initiate some form of a reward mechanism at least at the initial stages in order to establish a systematic CPD system in the country and to motivate the doctors for continuous learning.

Further, it was brought to light that although CPD organizing bodies have planned the activities, without seriously formulating goals or objectives, this raises many questions about the planning and implementation of CPD activities in the health care sector. However, evaluation of a programme is essential for improving the effectiveness and efficiency. On the other hand, there can be practical problems in evaluating programmes. However, if one decides to evaluate CPD programmes at least the level 1 of the Kirkpatrick's model (Kirkpatrick, 1994) most of the difficulties could be overcome.

Poor participation was identified as a major challenge in implementing of an effective CPD program. It could have been due to the reasons such as heavy work load, not relevant CPD activities to their practice, not relevant to individual learning needs, didactic passive CPD delivery models, lack of knowledge of importance of CPD and no legislations on CPD of doctors in Sri Lanka. Thus, it is important to provide structured CPD programmes for all the doctors in Sri Lanka. Since it is difficult to arrange face to face CPD activities for all the doctors, e-learning is a better option. It has been found that implementing a web based 
CPD programme in the field of medical genetics is feasible in the Sri Lankan context (Kulatunga et al., 2013). Thus, this trend should be explored by all the fields in medicine and higher authorities need to take serious note about it.

\section{Conclusions}

GMOs' perceive CPD as a dire need, most preferred learning methods and their practiced learning methods rely on immediately available learning resources, which have characteristics of familiarity, applicability and accessibility. The fact that learning needs have been averagely addressed in major hospitals and poorly addressed in peripheral hospitals requires consideration.

Hence, Ministry of Health needs to establish a mechanism to identify learning needs of doctors attached to both major hospitals and peripheral hospitals. Either legislation regarding CPD activities or reward systems and financial support for CPD activities are needed from the higher authorities. Further, majority of CPD organizing bodies in Sri Lanka is yet to establish an objective driven plan for CPD. Hence, collaboration between medical faculties, Ministry of Health and CPD providers is essential to set up high quality learning materials and to develop knowledge, skills and attitudes relevant to changing health care needs. Moreover, higher authorities need to train the CPD educators (specially, a responsible person who plans, designs and implements CPD systems) with ongoing research evidence to improve physicians' performance and health care outcomes.

\section{Acknowledgement}

We would like to extend our thanks to our study participants for participating in this study.

\section{Conflicts of interest}

The authors declare that they have no conflict of interests.

\section{References}

Abramson, J.H. \& Abramson, Z.H. (1999) Survey Methods in Community Medicine, 5th ed, Edinburgh, United Kingdom: Churchill Livingstone

Bandaranayake, R.C. (2009) Study skills In: Dent JA, Harden RM, A Practical Guide for Medical Teachers, 3rd ed. Toronto, Elsevier, pp. 385390
Bennett, N.L., Davis, D.A., Easterling, W.E., Friedmann, P., Green, J.S., Koeppen, B.M., Mazmanian, P.E. \& Waxman, H.S. (2000) Continuing medical education: a new vision of the professional development of physicians, Academic Medicine, 75, 12, pp. 1167-1172

Clemens, J.P. \& Gottlieb, J.D. (2013) [online] Do physicians' financial incentives affect medical treatment and patient health? American Economic Review, 104, 4, pp. 1320-1349. Social Science Research Network Available at http://ssrn.com/abstract=2101251 (Accessed on 12th Dec 2014)

Continuing professional development, Guidance for all doctors, General Medical Council (2012) [online] Available at http://www.gmcuk.org/Continuing professional development guidance for all doctors 0612.pdf 56438625.pdf (Accessed on 10th Aug 2014)

Craig, J. (1990) Perceived Learning Needs of Family Physicians in British Columbia, Canadian Family Physician, 36, p. 262

Davis, D.A., Thomson, M.A., Oxman, A.D. \& Haynes, R.B. (1995) Changing Physician Performance: A Systematic Review of the Effect of Continuing Medical Education Strategies, Journal of the American Medical Association, 274, 9, pp. 700705

Epa, S.S. (2003) Revalidation of Sri Lankan doctors, Ceylon Medical Journal, 48, 3, pp. 65- 67

Epa, S.S. (2010) National CPD certificate: Information and Guidance Book. Colombo: Sri Lanka Medical Association

Greene, J.C., Caracelli, V.J. \& Graham, W.F. (1989) American Educational Research Association toward a Conceptual Framework for MixedMethod Evaluation Designs Source, Educational Evaluation and Policy Analysis, 11, 3, pp. 255-274 Available at: http://www.jstor.org/stable/1163620 (Accessed on 07th Aug 2012)

Kingma, M. (1999) Can financial incentive influence medical practice? Human Resources for Health Development Journal, 3, pp. 121-131

Kirkpatrick, D.L. (1994) Evaluation, training programs: the four levels, San Francisco: Berrett-Koehler publishers. Learning transfer, International Journal of Training and Development, 6, 1, pp. 36-48

Kulatunga, G.A.K.G., Marasinghe, R.B., Karunathilake, I.M. \& Dissanayake, V.H.W. (2013) Development and implementation of a web-based continuing professional development (CPD) programme on medical genetics, Journal of Telemedicine and Tele care, 19, 7, pp. 388-392 
Madewell, J.E. (2004) Lifelong learning and maintenance of certificate, Journal of the American College of Radiology, 1, 3, pp. 199203

McClaren, J., Franco, E. \& Snell, L. (1998) Type of clinical problem is a determinant of physicians' self-selected learning methods in their practice settings, Journal of Continuing Education in the Health Professionals, 18, 2, pp. 107-118

Novick, G. (2008) Is There a Bias Against Telephone Interviews In Qualitative Research? Research in Nursing \& Health, 31, 4, pp. 391-398

Rancich, A.M., Perez, M.L., Morales, C. \& Gelpi, R.J. (2005) Beneficence, justice, and lifelong learning expressed in medical oaths, Journal of Continuing Education in the Health Professionals, 25, 3, pp. 211-220

Richards, T. (1998) Continuing medical education, needs to be more effective, accountable, and responsive to all stakeholders in health, British Medical Journal, 316, pp. 246
Sarkar, B.D. \& Kumar, S. (2004) Delays in legislation slow the progress of continuing medical education in India, Bulletin of World Health Organization, 82, pp. 154-155

Thompson, M.J., Skillman, S.M., Johnson, K., Schneeweiss, R., Ellsbury, K. \& Hart, L.G. (2002) Assessing physicians' continuing medical education (CME) needs in the U.S.associated Pacific jurisdictions, Pacific Health Dialog, 9, pp. 11-6

Towle, A. \& Cottrell, D. (1996) Self-directed learning, Archives of Disease in Childhood, 74, pp. 357359

Weiland, T.J., Dent, A.W. \& Paltridge, D. (2008) Australasian emergency physicians: A learning and educational needs analysis. Part Three: Participation by FACEM in available CPD: What do they do and do they like it? Emergency Medicine Australasia, 20, pp. 156-163

\section{Annexure -1}

\section{Continuing Professional Development (CPD) among grade medical officers}

Special Note- When you are completing this questionnaire please do not consider activities that are part of your postgraduate studies.

\section{Section A}

1. Sex

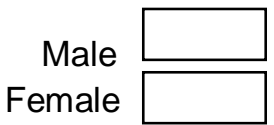

2. Age

3. Graduated Medical Faculty

- Peradeniya

- Colombo

- Kelaniya

- Jaffna

- Jayawardanapura

- Ruhuna

- Foreign

4. Year of graduation

5. Current post

6. Current place of work 
7. How long have you being working in the current place of work?

8. Post graduate studies

Completed

Currently following

None

9. If you have postgraduate qualifications, please specify

10. Are you studying for a postgraduate exam/other exam?

$10 \mathrm{a}$. If so please indicate the exam you are studying for?

\section{Section B}

1. In your opinion Continuing Professional Development (CPD) of doctors (please tick all that apply)

\begin{tabular}{|l|l|}
\hline is a professional responsibility of all doctors & \\
\hline promotes good medical practice & \\
\hline protects patients from substandard practice & \\
\hline helps doctors keeping up to date when they are not practicing & \\
\hline $\begin{array}{l}\text { means doctors should regularly take part in educational activities } \\
\text { that maintain and further develop competence/ performance }\end{array}$ & \\
across all areas of practice & \\
\hline don't know & \\
\hline other (please specify) & \\
\hline
\end{tabular}

2. Please indicate the type/s of CPD activities you have engaged in the past 12 months (Please tick all that apply)

\begin{tabular}{|l|l|}
\hline Attending hospital annual sessions & \\
\hline Attending distance learning programs & \\
\hline Attending international conferences & \\
\hline Attending local conferences & \\
\hline Reading journals & \\
\hline Reading medical text books & \\
\hline Teaching & \\
\hline Conducting audits/ research & \\
\hline Attending drug company events & \\
\hline Other (please specify) & \\
\hline
\end{tabular}

3. Why did you attend above CPD activities? (please tick all that apply)

\begin{tabular}{|l|l|}
\hline Very keen on professional development & \\
\hline For career progression & \\
\hline Due to discrepancies of Knowledge/ skills identified by you & \\
\hline Medical errors done by you/ colleague & \\
\hline Consultants (seniors) requested you to attend & \\
\hline Unit/ hospital policy & \\
\hline To collect CPD points & \\
\hline Other (please specify) & \\
\hline
\end{tabular}


4. a. Do you think CPD is needed for medical graduates?

Yes

No

If Yes

b. In your opinion should CPD be made mandatory or voluntary for medical officers?

Mandatory

Voluntary

If No

c. Please write reasons.

5. What is / are your best learning methods? (please tick all that apply)

\begin{tabular}{|l|l|}
\hline Listening to a lecture & \\
\hline Problem solving approach & \\
\hline Learning by reflecting on your own practice & \\
\hline Interactive learning (eg - small group discussions) & \\
\hline Reading & \\
\hline Work-based learning (practicing under supervision) & \\
\hline Other (please write) & \\
\hline
\end{tabular}

6. A. Please write about the most difficult/challenging clinical problem you faced recently.

B. How did you gain specific knowledge and skill to solve that problem? (eg - relevant reading)

7. Please write the three areas in which you would require CPD activities? (eg - Management of medical emergencies) 
8. What are your lifelong learning preferences / methods? (please indicate your best three preferences using $1,2,3$ )

\begin{tabular}{|l|l|}
\hline Attending lectures & \\
\hline Attending workshops & \\
\hline e - learning (learning through internet) & \\
\hline Reading medical textbooks & \\
\hline Reading journals & \\
\hline Learning during work from seniors & \\
\hline Attending courses offered by postgraduate institutes & \\
\hline By teaching to others & \\
\hline Other (please write) & \\
\hline
\end{tabular}

9. Please write the CPD activities conducted in your hospital?

10. Do you think that your learning needs are addressed by the CPD activities conducted in your Hospital?

Yes

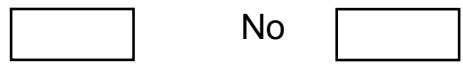

10 a. If No Please provides reasons.

11. What are the difficulties you have faced in relation to attending CPD activities (please tick all that apply)

\begin{tabular}{|l|l|}
\hline Excessive workload & \\
\hline Lack of motivation & \\
\hline Difficult to get leave & \\
\hline Cost & \\
\hline Not a government policy & \\
\hline No reward from the employer & \\
\hline Other (please specify) & \\
\hline
\end{tabular}


Grade Medical Officers perception towards lifelong learning

12. In your opinion who should provide CPD activities in Sri Lanka.(please select best one)

\begin{tabular}{|l|l|}
\hline Medical faculties & \\
\hline SLMA - Sri Lanka Medical Association & \\
\hline GMOA- Government Medical Officers Association & \\
\hline Clinical societies of the hospital & \\
\hline Colleges (ex- college of physicians ) & \\
\hline CPD committees & \\
\hline Other (please specify) & \\
\hline
\end{tabular}

13. a. Do you know about the National CPD Certificate recently introduced by the SLMA? Yes $\square$ No

$13 \mathrm{~b}$. If So, did you start collecting CPD points?

Yes No

14. If you know about the National CPD Certificate, what are the good points of the program?

15. If you know about the National CPD Certificate, what are the drawbacks of the program?

16. If so what are the suggestions to improve it.

Thank you very much for spending your valuable time to complete the survey. If you would like to receive provisional results, please write your e mail address below. 